\title{
De vaas van Heldring
}

Deze grote vaas is geheel bedekt met een geïriseerd groen loodglazuur.

De toepassing van loodglazuren op aardewerk was niet nieuw, maar werd in de Han-tijd (206 v.Chr.-221 n.Chr.) verder ontwikkeld. Uit opgravingen blijkt dat vooral dit type groene glazuur vanaf de tweede eeuw voor Christus veel werd gebruikt in Xi'an en omgeving. Door de economische voorspoed tijdens de Han-tijd en door de ontwikkeling van het gebruik om in het graf stukken keramiek mee te geven, groeide de productie snel en werd al spoedig op veel meer plaatsen dit aardewerk met loodglazuur gemaakt. Een opvallend kenmerk van deze keramiek is dat de vorm en decoratiemotieven vaak aan bronzen voorbeelden ontleend zijn. Bij de grote vaas die Ernst Heldring in 1938 aan de Vereniging schonk, is dat ook het geval. De vorm - hier veel gedrukter - komt weliswaar slechts in grote lijnen overeen met het bronzen vat uit de collectie Hülsmann (zie artikel Ellen Uitzinger eerder in dit nummer), voor de smalle horizontale banden en de taotie-maskers op de buik geldt dat veel sterker. Het geïriseerde glazuur doet bovendien denken aan een gepatineerd brons. De iets concave bodem is geglazuurd op drie kleine plekken langs de rand na, waar de pot gesteund is bij het bakken.

In het begin van de $20^{\mathrm{c}}$ eeuw was deze Han-keramiek in het Westen nog vrijwel onbekend. S.W. Bushell, (1844-1908), verbonden aan de Engelse legatie in Peking, had in 1897 het bestaan ervan als eerste gemeld. ${ }^{1}$ Kort daarna werd China door het eind van de Boxer-opstand (1901) toegankelijker voor buitenlanders en door de aanleg van spoorwegen kwam veel archeologisch materiaal boven de grond. In 1909 kon Berthold Laufer al een uitvoerig en rijk geillustreerd boek over Han-keramiek publiceren. ${ }^{2}$ In het grote formaat vazen - zo blijkt al uit deze eerste studie - zijn twee typen te onderscheiden. Iets gebruikelijker dan Heldrings vrijwel gladde vaas is de minder gedrukte vorm met op de schouder een band in reliëf met dieren en jagers.

Het oude China stond bij Westerse verzamelaars in die eerste jaren van de $20^{\mathrm{e}}$ eeuw in het brandpunt van de belangstelling. Enerzijds schakelden degenen die voordien vooral Japanse kunst verzamelden in deze jaren om verschillende redenen over op Chinese kunst, ${ }^{3}$ anderzijds bestond er in Amerika een groep zeer rijke verzamelaars die primair schilderijen verzamelden (vooral Hollandse meesters). De schilderijen werden aangevuld met andere kunstvoorwerpen, waaronder vaak renaissance beeldhouwwerk, Perzische tapijten, en bijna altijd Chinese keramiek. 'Pots and paintings', was een vaste combinatie in deze Amerikaanse gilded age (1865-1915). De verzameling had als doel culturele verfijning uit te drukken als tegenwicht voor de exorbitante rijkdom. Hoewel 'pots' aanvankelijk vooral porselein uit de $17^{\mathrm{c}}$ en $18^{\mathrm{e}}$ eeuw betekende, werd dit aan het begin van de $20^{\mathrm{e}}$ eeuw uitgebreid met vroegere stukken, zoals ook grote Han-vazen. Zo kwamenee access 

verschillende soorten verzamelaars rond dezelfde tijd bij hetzelfde verzamelonderwerp uit. De Amerikaanse verzamelars waren zo kapitaalkrachtig dat ze een stevig stempel drukten op de markt en daardoor ook mede bepaalden wat wel en niet het verzamelen waard werd geacht. Een voorbeeld van een collectie 'pots and paintings' is de verzameling van Henry Osborne Havemeyer (1847-1907). ${ }^{5}$ Havemeyer had als suikerbaron een fortuin vergaard en verzamelde schilderijen, pastels, prenten, Chinese keramiek, Japanse kunstvoorwerpen. Door een legaat van zijn weduwe kwam zijn collectie in 1929 in het Metropolitan Museum in New York terecht.

Onder deze omstandigheden groeide een Han-vaas in korte tijd uit tot een begerenswaardig verzamelobject, en dat gold ook voor de leden van de Vereniging. G.J. Verburgt, medeoprichter en bestuurslid van de Vereniging kocht een vaas met een jachtscène in reliëf in 1912 bij de firma Wannieck in Parijs. In Leeuwarden kocht Nanne Ottema (1874-1955), eveneens bestuurslid van de Vereniging een dergelijke vaas in 1917 bij de firma $\mathrm{D}$. Komter in Amsterdam. ${ }^{6}$ Wanneer en bij wie Heldring zijn vaas kocht is niet meer na te gaan, maar wel is bekend dat hij de vaas in 1938 aan de Vereniging schonk ter gelegenheid van het 20 -jarig bestaan. Op 1 juni van dat jaar werd in aanwezigheid van burgemeester De Vlugt het Museum van Aziatische Kunst in enkele zalen van het Stedelijk Museum na een verbouwing van twee en een halve maand weer geopend en tevens het vierde lustrum gevierd.

Zoals door Renée Steenbergen in haar inleiding beschreven is, was Ernst Heldring (1871-1954) in de eerste helft van de $20^{\circ}$ eeuw een invloedrijk man in Nederland. Het bestuurslidmaatschap van de Vereniging was slechts een van de vele activiteiten die hij naast zijn werk als ondernemer ontplooide. Zijn rol als fondsenwerver én donor kwamen in het artikel van Steenbergen al aan de orde. Vanuit dat perspectief is het geschenk van Heldring goed te begrijpen. Hij droeg op deze manier nog eens extra bij aan de totstandkoming van een collectie van de Vereniging, de keuze paste precies in de doelstelling en de vaas is een variant op het bekendere type dat weliswaar toen nog niet in de collectie van de Vereniging vertegenwoordigd was, maar wel al in de collectie van medeoprichter Verburgt.

Heldring had belangstelling voor Europese en Aziatische kunst. In 1949 schonk hij een bronzen beeldje van Brahma (Java, $9^{c}$ eeuw) en na zijn dood ontving de Vereniging als legaat nog verschillende voorwerpen, vooral Japanse wapens en delen van wapenrusting. ${ }^{7}$

\section{Noten}

1. In Oriental Ceramic Art, New York, 1897, p. 10.

2. Chinese pottery of the Han dynasty, Leiden, 1909. Laufer deed in 1903 in China onderzoek naar Han-keramiek. De snelle verspreiding van Han-potten blijkt uit enkele vroege verwervingen van musea. Het museum in Boston had al vroeg een exemplaar, zoals blijkt uit de publicatie Chinese pottery and porcelain van R.L. Hobson uit 1915 (pl. 2 , fig. 1). Musée Guimet heeft een dergelijke pot die verzameld werd op de 'mission Pelliot' in 1906-1910, zie Oriental ceramics; the world's great collections. Vol. 8 Musée Guimet, Tokyo, 1976-1978, nr. 3. Samuel T. Peters, een vroege verzamelaar van Chinese keramiek in New York en trustee van het Metropolitan Museum bezat een grote Han-vaas, die door een legaat van zijn

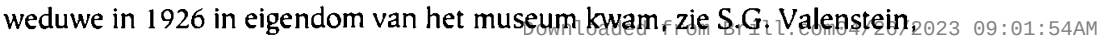
A handbook of Chinese ceramics, New York, 1975, pl. 41, p. 47. 
3. Dit zou zo rond 1905 hebben plaatsgevonden, zie W.I. Cohen, East Asian Art and American culture; a study in international relations, New York, 1992, p. 45.

4. W. Liedtke, 'Hollandse schilderijen in Amerika; de verzamelaars en hun idealen', Hollandse Meesters uit Amerika (tent.cat. Mauritshuis) Den Haag/Zwolle, 1990, pp. 14-59.

5. A.C. Freylinghuysen e.a., Splendid legacy; the Havemeyer collection (tent.cat Metropolitan Museum), New York, 1993. De vaas is in deze publicatie niet afgebeeld. Wel in: Oriental ceramics; the world's great collections. Vol. 12 The Metropolitan Museum of Art, Tokyo, 1976-1878, zwart wit plaat 12. Andere exemplaren die sterk overeenkomen: R. Krahl, Chinese ceramics from the Meiyintang collection, Londen, 1994, Vol. 1, nr. 80; Oriental ceramics; the world's great collections. Vol. 10 The Freer Gallery of Art, Tokyo, 1976-1878, nr. 4; Laufer, Op.cit. (noot 1), pl. XXXIX, nr. 1 en pl. XLV; en het exemplaar in Hobson, zie noot 1.

6. Inv.nr. NO 1429.

7. Beeld van Brahma AK-MAK-249; AK-MAK-296 Japans beeld; AK-MAK-327 Japans zwaard; AK-MAK-380, 381, 382, 383, 384 Japanse zwaarden; AK-MAK-386 deel van een Japans harnas; AK-MAK-301 Koreaanse schildering; AK-MAK-29l Chinese schildering; AK-MAK-257 Javaanse kris; AK-MAK-260 Javaanse kris; AK-MAK-155 Japanse stijgbeugels; AK-MAK 129 Japanse dolk; AK-MAK 130 Japans pistool; AKMAK-131 Japanse stijgbeugels; AK-MAK-132, 133, 134, 135, 136, 137 Japanse helm; AK-MAK-138 deel van een Japans harnas. 